\title{
Lack of Tumor Necrosis Factor-Related Apoptosis-Inducing Ligand But Presence of Its Receptors in the Human Brain
}

\author{
Jan Dörr, ${ }^{1 *}$ Ingo Bechmann, ${ }^{2 *}$ Sonia Waiczies, ${ }^{1 *}$ Orhan Aktas, ${ }^{1}$ Henning Walczak, ${ }^{3}$ Peter H. Krammer, ${ }^{4}$ \\ Robert Nitsch, ${ }^{2 *}$ and Frauke Zipp ${ }^{1 *}$ \\ ${ }^{1}$ Department of Neurology, Division of Neuroimmunology and 2Institute of Anatomy, Department of Cell- and

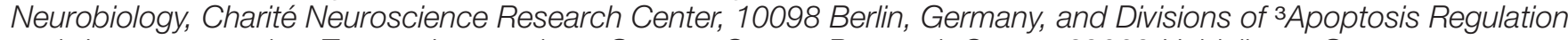 \\ and 4/mmunogenetics, Tumour Immunology, German Cancer Research Center, 69009 Heidelberg, Germany
}

Apoptosis mediated by members of the tumor necrosis factor (TNF)-nerve growth factor superfamily plays a crucial role in the interaction of the nervous and the immune system. On the one hand, it is involved in the defense mechanisms of the brain, the immune privilege. On the other hand, it is involved in the induction of glial-neuronal cell death in neuroinflammatory diseases. Here, we show that in contrast to the other known death ligands, TNF-related apoptosis-inducing ligand (TRAIL) is not constitutively expressed in the human brain, whereas both apoptosis-mediating and apoptosis-blocking TRAIL receptors

The CNS is an immune-privileged organ like the placenta, anterior chamber of the eye, and testes. One mechanism of maintaining immune privilege is that invading $\mathrm{T}$ cells undergo apoptosis (Pender et al., 1991; Schmied et al., 1993), mediated via death receptor-ligand interactions. This was shown for both the tumor necrosis factor (TNF) receptor-TNF (Bachmann et al., 1999) and the CD95-CD95 ligand (Gold et al., 1997; Bechmann et al., 1999, 2000; Flügel et al., 2000) systems. Furthermore, as a potent inducer of apoptosis, TNF-related apoptosis-inducing ligand (TRAIL, also known as APO-2L) (Wiley et al., 1995; Pitti et al., 1996), a member of the TNF superfamily, has been demonstrated to be involved in providing and maintaining immune privilege in human placenta (Phillips et al., 1999). For TRAIL, both apoptosis-inducing and nonapoptosis-inducing membrane-bound receptors have been described. The ability for transmission of a death signal is restricted to TRAIL receptor 1 (TRAIL-R1, DR4) (Pan et al., 1997a) and TRAIL-R2 (DR5) (Sheridan et al., 1997; Walczak et al., 1997). TRAIL-R3 (DcR1, TRID) and TRAIL-R4 (DcR2, TRUNDD) are truncated and have been suggested to act as decoy receptors by binding TRAIL without transmitting a death signal, thereby inhibiting apoptosis (Sheridan et al., 1997; Pan et al., 1997b; Degli-Esposti et al., 1997a,b).

Depending on the localization of the ligand and its receptors,

\footnotetext{
Received Oct. 30, 2001; revised Oct. 30, 2001; accepted Nov. 21, 2001.

This work was supported by Gemeinnützige Hertie-Stiftung and Deutsche Forschungsgemeinschaft Grants ZI 448/7-1 (F.Z.), BE 2272/1-1 (I.B.), and SFB 507/C1 (R.N.), and the Bundesministerium für Bildung und Forschung to H.W. (BioFuture). We thank T. N. Lehmann from the Neurosurgery Department and F. v. Landeghem from the Neuropathology Department for providing fresh human brain material, K. Hertwig for providing fresh human placenta material, and Heiko Stahl for excellent technical assistance.

*J.D., I.B., S.W., R.N., and F.Z. contributed equally to this work.

Correspondence should be addressed to Dr. Frauke Zipp, Department of Neurology, Division of Neuroimmunology, Neuroscience Research Center NWFZ 2680, Charité Campus Mitte, Schumannstrasse 20/21, 10117 Berlin, Germany. Email: frauke.zipp@charite.de.

Copyright (ㄷ) 2002 Society for Neuroscience $\quad 0270-6474 / 02 / 220001-05 \$ 15.00 / 0$
}

are found on neurons, astrocytes, and oligodendrocytes. Thus, the brain differs from other immune-privileged organs, such as the placenta, with the TRAIL receptor-TRAIL system not being part of the immune privilege of the brain. Conversely, this death receptor-ligand system might well play an important role in $\mathrm{T}$ cell-mediated autoimmune diseases of the CNS such as multiple sclerosis.

Key words: TRAIL; TRAIL receptor; apoptosis; immune privilege; brain; $M S$

the TRAIL system can act in two ways: death ligands expressed on resident parenchymal cells can induce apoptosis in infiltrating lymphocytes, or conversely, infiltrating lymphocytes may induce apoptosis in resident parenchymal cells via death ligands. The TRAIL receptor-TRAIL system thus could play a role in the control of $\mathrm{T}$ cell invasion as well as their destructive actions in the brain. Because of its particular properties, including membranous expression of apoptosis-mediating and apoptosis-blocking receptors and apoptosis-independent antiproliferative mechanisms (Song et al., 2000; Hilliard et al., 2001), this system might be involved in the pathogenesis of $\mathrm{T}$ cell-mediated autoimmune diseases such as multiple sclerosis (MS). In fact, TRAIL was found to be upregulated in peripheral immune cells of MS patients (Huang et al., 2000). Upregulation of TRAIL on human antigen-specific T cells after activation (Wendling et al., 2000), as well as the induction of apoptosis in acute brain slices after TRAIL application (Nitsch et al., 2000), further indicate a possible role for this system in glial-neuronal damage in $\mathrm{T}$ cellmediated disorders such as MS.

In this study, RT-PCR, Western blot analysis, and doublelabeling immunocytochemistry were applied to study the expression of TRAIL and the distribution of its membrane-bound

This article is published in The Journal of Neuroscience, Rapid Communications Section, which publishes brief, peerreviewed papers online, not in print. Rapid Communications are posted online approximately one month earlier than they would appear if printed. They are listed in the Table of Contents of the next open issue of JNeurosci. Cite this article as: JNeurosci, 2002, 22:RC209 (1-5). The publication date is the date of posting online at www.jneurosci.org.

http://www.jneurosci.org/cgi/content/full/6087 
receptors on the transcriptional and translational level in human brain tissue obtained from individuals undergoing craniotomy because of epilepsy. Whereas TRAIL expression was not detected in the brain, both apoptosis-inducing and nonapoptosisinducing receptors were found.

\section{MATERIALS AND METHODS}

Cell lines, brain, and placenta tissues. CV-1/EBNA cells were purchased from American Type Culture Collection (Manassas, VA) and were cultured in DMEM. The medium was supplemented with $10 \%$ fetal bovine serum, $5 \mathrm{~mm}$ L-glutamine, $100 \mathrm{U} / \mathrm{ml}$ penicillin, and $100 \mu \mathrm{g} / \mathrm{ml}$ streptomycin. Cells were kept at $37^{\circ} \mathrm{C}$ in a $5 \% \mathrm{CO}_{2}$ atmosphere.

Because no antibody available achieved staining in postmortem tissue, all human brain tissue samples $(n=10)$ used in this study were fresh ex vivo material obtained from four different individuals undergoing temporal lobe resection because of epilepsy. Tissue was either frozen in liquid nitrogen and stored at $-80^{\circ} \mathrm{C}$ or immediately taken up in RNA isolation buffer (see "RT-PCR"). Human placenta was used as positive control. Fresh placenta was washed in PBS and thereafter stored at $-80^{\circ} \mathrm{C}$.

$R T-P C R$. Total RNA was isolated according to standard protocols using the PeqGold TriFast isolation kit (Peqlab, Erlangen, Germany). Fresh brain tissue was taken up in TriFast reagent and separated by syringe and cannula. Frozen brain material (to confirm data) and placenta were ground in a mortar in the presence of liquid nitrogen to avoid RNA degradation and subsequently taken up in the TriFast reagent. Contamination with genomic DNA was excluded by performing DNAdigestion using DNase I (Boehringer Mannheim, Mannheim, Germany). Subsequently, RNA was quantified photometrically by absorbance at 260 $\mathrm{nm}$. We used $1 \mu \mathrm{g}$ of RNA as a template for random-primed cDNA synthesis using a first-strand cDNA synthesis kit (Pharmacia Biotech, Freiburg, Germany). To exclude amplification of any remaining genomic DNA, a no-RT control was performed. A negative control without template cDNA was run with every PCR. No specific PCR signal was detected under these control conditions. PCR was accomplished in a final volume of $50 \mu \mathrm{l}$ using a recombinant Taq polymerase kit (Invitrogen, Karlsruhe, Germany). The PCR conditions were as follows: glyceraldehyde-3-phosphate-dehydrogenase (G3PDH): 26 cycles, $45 \mathrm{sec} /$ $95^{\circ} \mathrm{C}, 45 \mathrm{sec} / 54^{\circ} \mathrm{C}, 60 \mathrm{sec} / 72^{\circ} \mathrm{C}$, primer sequences GTCAACGGATTTGGTCGTATT and AGTCTTCTGGGTGGCAGTGAT (NM002046, nucleotides 97-118 and 616-636); TR AIL-R1: 35 cycles, $45 \mathrm{sec} / 95^{\circ} \mathrm{C}, 45 \mathrm{sec} / 60^{\circ} \mathrm{C}, 60 \mathrm{sec} / 72^{\circ} \mathrm{C}$, primer sequences ACTCGCTGTCCACTTTCGTCTCTGA and CATCCCCTGGGCCTGCTGCTGTA (U90875, nucleotides 911-935 and 1200-1219); TRAIL-R2: 35 cycles, $45 \mathrm{sec} / 95^{\circ} \mathrm{C}, 45 \mathrm{sec} / 60^{\circ} \mathrm{C}, 60 \mathrm{sec} / 72^{\circ} \mathrm{C}$, primer sequences GGGAGCCGCTCATGAGGAAGTT and CTGGGTGATGTTGGATGGGAGAGT (AF012535, nucleotides 1113-1134 and 1495-1518); TRAIL-R3: 33 cycles, $45 \mathrm{sec} / 95^{\circ} \mathrm{C}, 45 \mathrm{sec} / 72^{\circ} \mathrm{C}, 45 \mathrm{sec} / 72^{\circ} \mathrm{C}$, primer sequences GAAGAATTTGGTGCCAATGCCACT and CTCTTGGACTTGGCTGGGAGATGT (AF016267, nucleotides 638-662 and 1224-1248); TRAIL-R4: 32 cycles, $45 \mathrm{sec} / 95^{\circ} \mathrm{C}, 45 \mathrm{sec} / 64^{\circ} \mathrm{C}, 60 \mathrm{sec} /$ $72^{\circ} \mathrm{C}$, primer sequences CAACTGGTGGGCTCCGAAAAG and ACCGCATGTGGCCTAAAACGAC (AF029761, nucleotides 111751195 and $1500-1521)$; TR AIL: 26 cycles, $45 \mathrm{sec} / 95^{\circ} \mathrm{C}, 45 \mathrm{sec} / 55^{\circ} \mathrm{C}, 60$ sec $/ 72^{\circ} \mathrm{C}$, primer sequences CACATTGTCTTCTCCAAACTC and GTCCATGTCTATCAAGTGCTC (U37518, nucleotides 489-509 and 874-894). As a control for TRAIL expression, an additional primer set was used as described by Frank et al. (1999), 30 cycles, $45 \mathrm{sec} / 95^{\circ} \mathrm{C}$, $45 \mathrm{sec} / 52^{\circ} \mathrm{C}, 60 \mathrm{sec} / 72^{\circ} \mathrm{C}$, primer sequences TGGGACCAGAGGAAGAAG and TTGGGAATAGATGTA (U37518, nucleotides 467-485 and 634-648).

Antibody specificity. Specificity of antibodies was tested using CV-1/ EBNA cells selectively expressing solely TRAIL or one of its receptors, respectively. CV-1/EBNA cells were transiently cotransfected essentially as described (Walczak et al., 1997). Here, we transfected the cells on cover slides and used a mix of three different plasmids in each transfection: (1) either one of the following five plasmids: pCDNA3 (Invitrogen, San Diego, CA) or pCDNA3.1 that encoded full-length human TRAIL-R1 to -R4 or full-length human TRAIL, respectively; (2) a plasmid that encodes the anti-apoptotic Baculovirus protein $\mathrm{p} 35$, and (3) pSV3-Neo that encodes the large $\mathrm{T}$ antigen necessary for the replication of pCDNA3 in CV-1/EBNA cells. Forty-eight hours after transfection, the cells were washed twice with PBS and were then fixed for $10 \mathrm{~min}$ at room temperature in PBS containing $4 \%$ paraformaldehyde. Last, the cells were washed again twice with PBS, and the cover slides were then dried and stored at room temperature. The cells were subjected to immunocytochemical stainings using the same antibodies and fluorescence labeling protocol as used for immunocytochemical stainings of human brain slices (see below).

Western blot. Triton-X protein extracts were obtained by homogenization of frozen brain tissue in the presence of protease inhibitors $(0.5$ $\mu \mathrm{g} / \mathrm{ml}$ leupeptin, $1 \mu \mathrm{g} / \mathrm{ml}$ pepstatin, and $0.2 \mathrm{~mm}$ phenylmethylsulfonyl fluoride), centrifugation at $1000 \times g$ for $10 \mathrm{~min}$ to remove nuclei and undissolved material, and a further 20 min centrifugation at 17,000 $\times g$. Homogenization and protein handling were always performed in a $4^{\circ} \mathrm{C}$ environment. Lysates equivalent to $50 \mu \mathrm{g}$ of protein, as determined by the bicinchoninic acid (BCA) method (Pierce, Rockford, IL), were separated using $10 \%$ polyacrylamide gel electrophoresis and blotted onto nitrocellulose membranes using standard procedures. After $2 \mathrm{hr}$ incubation at room temperature in a blocking cocktail $(5 \%$ milk powder, $2 \%$ BSA in $0.01 \mathrm{M}$ Tris- $\mathrm{HCl}$, and $0.1 \%$ Tween 20 ), membranes were incubated overnight at $4{ }^{\circ} \mathrm{C}$ or for $1 \mathrm{hr}$ at room temperature with the following specific primary antibodies: polyclonal rabbit anti-TRAIL-R1 (AB1139 from Alexis, San Diego, CA) and polyclonal rabbit anti-TRAIL-R2 (AB16942 from Chemicon, Hofheim, Germany) were used at a concentration of $2 \mu \mathrm{g} / \mathrm{ml}$, polyclonal goat anti-TRAIL-R3 (210-744-R100 from Alexis) at $1 \mu \mathrm{g} / \mathrm{ml}$, and polyclonal rabbit anti-TRAIL-R4 (AB16943 from Chemicon International) at $1 \mu \mathrm{g} / \mathrm{ml}$. Antibodies were diluted in solutions of blocking buffer in PBS-Tween 20. After a series of washing steps, the membranes were incubated for $1 \mathrm{hr}$ with $1.3 \mu \mathrm{g} / \mathrm{ml}$ anti-rabbit secondary antibody or $0.17 \mu \mathrm{g} / \mathrm{ml}$ anti-goat secondary antibody, coupled to horseradish peroxidase (both Dako, Hamburg, Germany). Specific bands were detected using the ECL-plus system (Amersham Pharmacia Biotech, Uppsala, Sweden).

Immunocytochemistry. Directly after removal from the skull (brain) or postpartum (placenta), the tissue was fixed in $4 \%$ paraformaldehyde in $0.1 \mathrm{M}$ phosphate buffer (PB) for $6 \mathrm{hr}$ at $4^{\circ} \mathrm{C}$. Twenty-micrometer-thick sections were cut on a vibratome. These sections were then incubated in $10 \% \mathrm{H}_{2} \mathrm{O}_{2}$ for 10 min to block endogenous peroxidases, washed several times in PB, and stored for $30 \mathrm{~min}$ in a solution containing $10 \%$ serum from the species of the secondary antibodies in $0.1 \mathrm{M}$ phosphate buffer to minimize background staining. The tissue was then incubated overnight at $4^{\circ} \mathrm{C}$ in a solution containing $0.1 \%$ Triton $\mathrm{X}-100,1 \%$ serum, and the primary antibodies. Antibody concentration was optimized using increasing dilutions of each antibody, respectively. Final dilutions of antibodies used in this study were as follows: anti-TRAIL: D3 1:100, H257 1:200, M19 1:100 (all Santa Cruz Biotechnology, Santa Cruz, CA), B35-1 1:500 (PharMingen, San Diego, CA), 210-732-R100 1:75 (Alexis); antiTRAIL-R1: AB1139 1:100 (Alexis); anti-TRAIL-R2: AB16942 1:50 (Chemicon); anti-TRAIL-R3: AB210-744-R100 1:200 (Alexis); and anti-TR AIL-R4: AB16943 1:250 (Chemicon). Controls were performed by omitting the primary antibodies and using isotype control antibodies (mouse, FLOPC-21, Sigma, Deisenhofen, Germany; rabbit, X 0936 , Dako). Under these conditions, no specific immunostaining was observed in our material.

Immunolabeling of TRAIL and its receptors was visualized with fluorescein isothiocyanate-coupled secondary antibodies (1:500; Sigma) These sections were then counterstained for neurons, oligodendrocytes, astrocytes, and microglial cells using antibodies against microtubuleassociated protein (mouse anti-MAP-2, 1:500; Sigma), phospholipoprotein (rabbit anti-PLP, 1:1000; Serotec, Oxford, UK), glial fibrillary acidic protein (rabbit anti-GFAP, 1:1000; Dako), and CD68 (mouse anti-CD68, 1:100; Dako), respectively. These markers were visualized using trimethylrhodamine-coupled secondary antibodies (diluted 1:500).

\section{RESULTS}

To detect and localize TRAIL receptor/TRAIL expression in human brain, RT-PCR, Western blot analysis, and immunocytochemistry were performed on brain tissue freshly obtained from epilepsy surgery. Both, apoptosis-mediating (TRAIL-R1 and -R2) and nonapoptotis-mediating (TRAIL-R3 and-R4) TRAIL receptors were expressed in the adult brain, exemplarily demonstrated in Figure $1 a$. Bands of the expected sizes were detected for TRAIL-R1 to -R4. Conversely, no TRAIL expression could be identified in all brains analyzed. We confirmed TRAIL expression on the RNA level in human placenta, which we subsequently used as positive control (Fig. 1a). Moreover, the lack of 

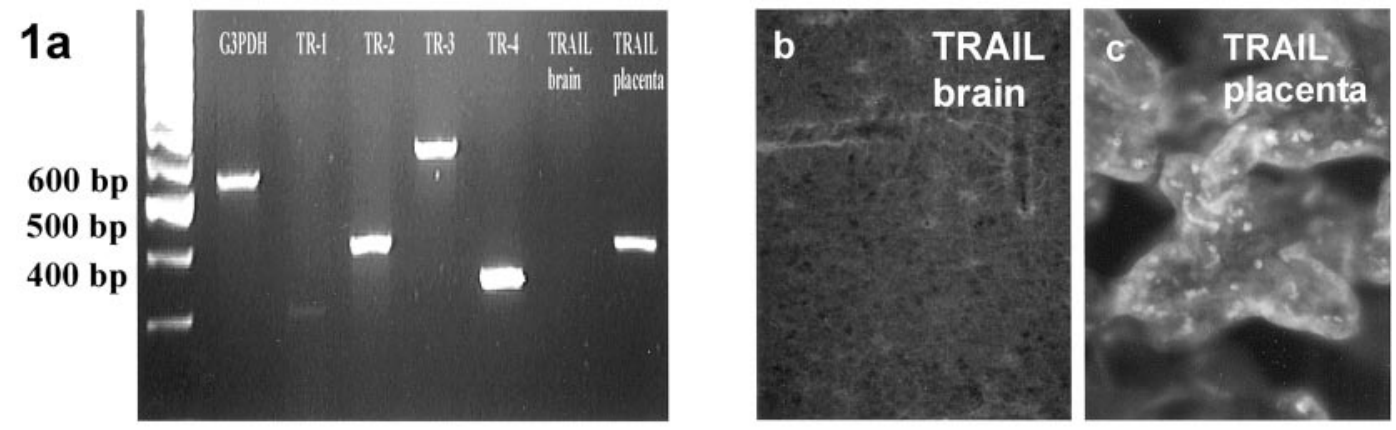

Figure 1. Expression pattern of TRAIL receptors and TRAIL in human brain. $a$, RNA isolated from human brain tissue was analyzed by RT-PCR with primers specific for TRAIL-R1 to R4 and TRAIL. Functionality of the TRAIL-specific primer pair is demonstrated by a signal obtained from TRAIL-positive placenta material. $b$, The lack of TRAIL expression in the human brain is demonstrated by immunocytochemistry. No TR AIL-specific signal could be detected in human brain sections derived from epilepsy patients with any of the five anti-TRAIL antibodies (see Materials and Methods). $c$, To exclude that the lack of TR AIL signals in the brain is caused by methodological problems of the immunocytochemistry, the antibodies were tested in human placenta. All tested antibodies clearly recognized TRAIL on cells in the human placenta. The picture shows staining with M19 antibodies. Magnifications: $b, c, 20 \times$.

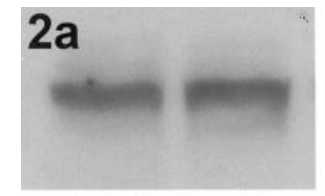

TRAIL-R1

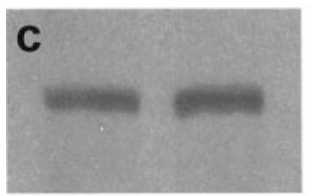

TRAIL-R3

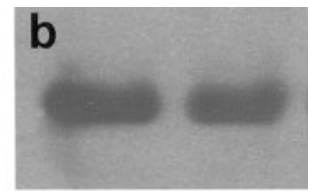

TRAIL-R2

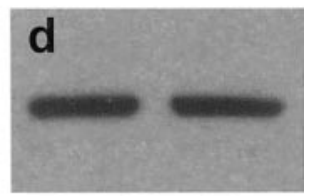

TRAIL-R4
Figure 2. Western blot analysis of TRAIL receptors in the human brain. Presence of TRAIL-R1 is demonstrated by a specific band $(\sim 60 \mathrm{kDa})$ obtained with AB1139 (a), of TRAIL-R2 $(\sim 50 \mathrm{kDa})$ with AB16942 (b), of TRAIL-R3 ( 75 kDa, oligomer) with 210-744-R100 (c), and of TRAIL-R4 ( $\sim 35 \mathrm{kDa})$ with AB16943 $(d)$.

TRAIL was confirmed by RT-PCR using previously published TRAIL-specific oligonucleotides (Frank et al., 1999). These authors demonstrated TRAIL expression in human brain tumors and in brain samples adherent to removed debris from patients with severe penetrating brain injuries, which they assessed as normal CNS tissues. In our material, even raising the cycle numbers did not result in the detection of TRAIL mRNA by RT-PCR of freshly isolated human brain, whereas TRAIL mRNA was readily detected with this method in T cells (Wendling et al., 2000).

Immunocytochemically, using five different antibodies, no TRAIL was detected in the parenchyma either (Fig. 1b). Intense signals in the same tissue on some perivascular and pial macrophages known to express TRAIL as well as in human placenta, as a positive control (Fig. 1c), ruled out the possibility of methodological restrictions.

Western blot analysis demonstrated the presence of all four TRAIL receptors in the human brain (Fig. $2 a-d$ ). To evaluate whether TRAIL receptor expression was restricted to distinct cell populations in the brain, subsequent immunocytochemical double-staining experiments were performed (Fig. 3a-l). Immunostaining with the AB1139 antibody specific for human TRAIL-R1 revealed a specific fluorescence signal (Fig. $3 a$ ) that could be localized to astrocytes by GFAP costaining (Fig. 3b). TRAIL-R2 was identified on both oligodendrocytes as demonstrated by double-fluorescence staining with AB16942 and PLP antibody (Fig. 3c,d) and neurons counterstained with MAP-2 antibody (Fig. 3e,f). TRAIL-R3 protein, stained with 210-744$\mathrm{R} 100$, was predominantly found on cells exhibiting the typical morphology of neurons (Fig. $3 g, h$ ). TRAIL-R4 protein detected by AB16943 was heavily expressed on oligodendrocytes (Fig. 3i,j) and on neurons (Fig. $3 k, l$ ). Interestingly, we were unable to detect expression of TRAIL receptor protein on microglial cells, as confirmed by anti-CD68 counterstaining (data not shown).

\section{DISCUSSION}

Performing RT-PCR and using five different anti-TRAIL antibodies, we failed to detect the ligand in nontransformed, noninflammatory human brains (Fig. 1) while demonstrating the presence of TRAIL receptors in the brain (Fig. 2) localized on neurons, astrocytes, and oligodendrocytes (Fig. 3). Because all antibodies available could not be used in autopsy material, we used fresh biopsy tissue obtained from epilepsy patients undergoing temporal lobe resection. We are aware of the fact that in epilepsy animal models, neuronal apoptosis has been described (Tuunanan et al., 1999). However, all these studies refer to status epilepticus-induced neuronal damage, which was not the case in the brains used in our study. The absence of TRAIL in the human brain reported here is in line with a lack of TRAIL expression in peritumoral brain tissue (Rieger et al., 1999). This is with the exception of reactive astrocytes in the area surrounding brain malignancies, as immunocytochemically demonstrated.

For a death receptor-death ligand system involved in the mechanisms of immune privilege, one would expect constitutive expression of the ligand in the respective immune-privileged tissue allowing removal of infiltrating $\mathrm{T}$ cells as already shown for TRAIL in human placenta (Phillips et al., 1999) and for CD95 ligand in human eye (Griffith et al., 1995), brain (Bechmann et al., 1999), and testes (Bellgrau and Duke, 1999). Thus, the lack of TRAIL expression in the human brain argues against its role as a self-defense mechanism involved in immune privilege. On the other hand, presence of TRAIL receptors on neurons, astrocytes, and oligodendrocytes points to a unique role of this apoptosisregulating system for the brain when compared with other systems, such as TNF receptor-TNF and CD95-CD95 ligand. The expression of the apoptosis-mediating TRAIL receptors on neu- 

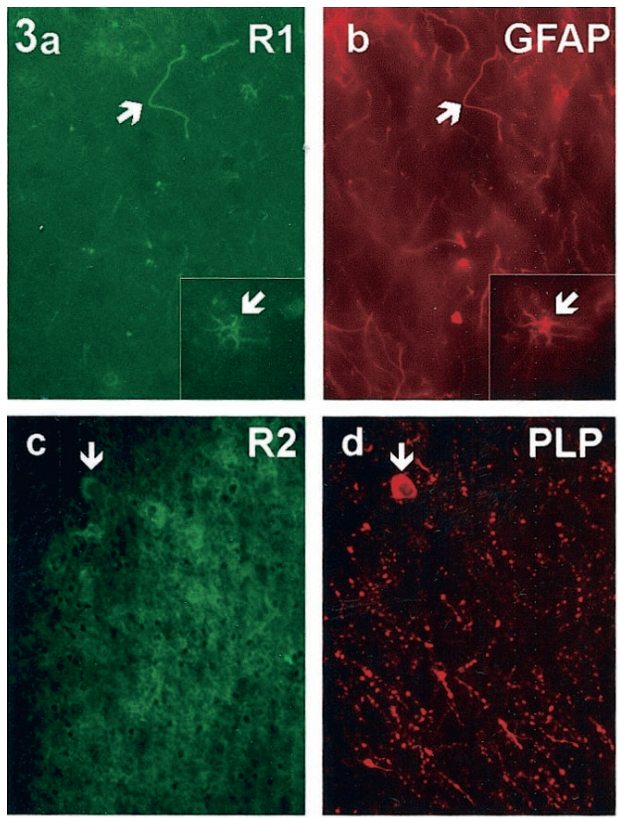

Figure 3. Human brain sections were double stained with antibodies against TRAIL receptors and neuronal $(M A P)$, astrocyte $(G F A P)$, or oligodendrocyte (PLP) markers to detect colocalization. Arrows point to those cells that are clearly double stained, whereas arrowheads indicate monolabeled structures indicating specificity of fluorescence filters. Expression of TRAIL-R1 was detected with $\operatorname{AB} 1139(a)$ and could be localized to astrocytes by GFAP costaining $(b)$. TRAIL-R2 was identified by AB16942 $(c, e)$ and can be found on both oligodendrocytes $(d)$ and neurons $(f)$. TRAIL-R3 was found on neurons by using 210-744-R100 $(g, h)$. TRAIL-R4 was detected by using the $\mathrm{AB} 16943(i, k)$. Expression of this receptor could also be attributed to both oligodendrocytes and neurons $(j, l)$. Magnifications: $a-f, 40 \times ; g, h, 20 \times ; i-l, 40 \times$.
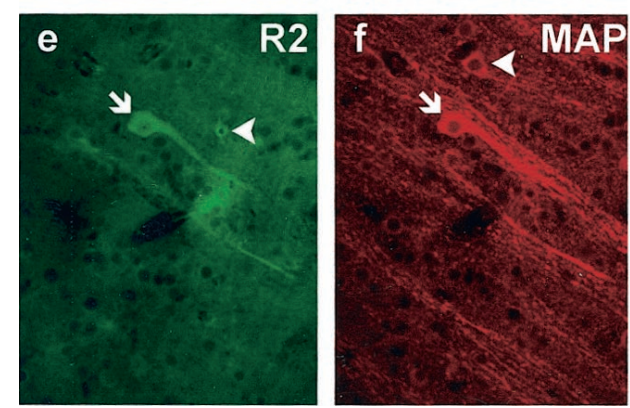
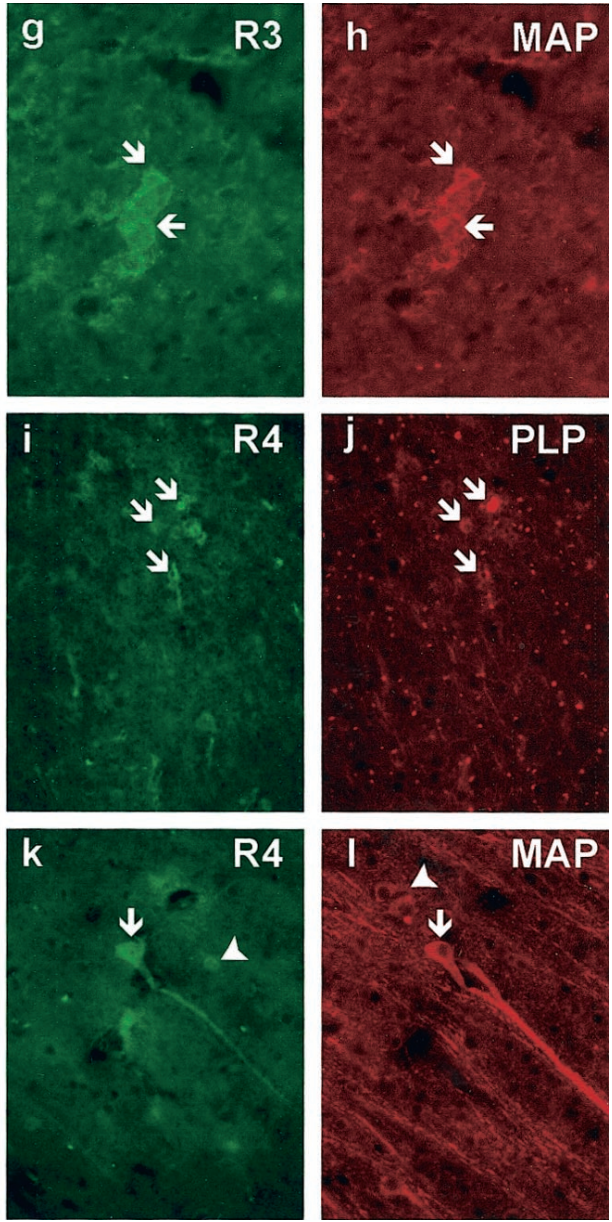

rons, astrocytes, and oligodendrocytes indicates their possible susceptibility to TRAIL-mediated apoptosis. The scenario might be that T cells, which upregulate TRAIL after activation (Wendling et al., 2000), invade the brain and induce cell death of parenchymal cells via TRAIL receptor-TRAIL interaction. These activated $\mathrm{T}$ cells downregulate agonistic TRAIL receptors and are not susceptible to undergoing TRAIL-mediated apoptosis (Wendling et al., 2000). In fact, we were able to demonstrate glioma cell death induced by $\mathrm{T}$ cells via TRAIL receptorTRAIL interaction (Dörr et al., 2001). Moreover, induction of apoptosis in brain parenchymal cells including neurons, astrocytes, and oligodendrocytes by TRAIL has been observed in acute human brain slices (Nitsch et al., 2000). The present data thus provide a molecular basis for these findings because deathmediating TRAIL receptors are present on parenchymal cells in the brain which, under physiological conditions, lacks the deathinducing ligand.

The expression of apoptosis-mediating TRAIL receptors, as described in our study, indicates that neurons, astrocytes, and oligodendrocytes are potentially susceptible to an attack by TRAIL-expressing T cells. Because both apoptosis-mediating as well as apoptosis-blocking receptors are present on the different brain parenchymal cells, the actual regulation of receptor subtype expression might be crucial for the fate of an individual cell. It is conceivable that dysregulation of this expression under pathological conditions can substantially affect their survival in the circumstance of an inflammatory $\mathrm{T}$ cell invasion. Induction of cell death by TRAIL in the human brain (Nitsch et al., 2000), to- gether with our present data, indicate a potential role for the TRAIL receptor-TRAIL system as an effector mechanism in neuroinflammation such as MS rather than a role in defense mechanisms of the immune-privileged brain. These findings render the TRAIL system an efficient therapeutic target in neuroinflammation, which circumvents the shortcomings of TNFtargeted strategies that have failed (van Oosten et al., 1996; The Lenercept MS Study Group, 1999), presumably because of the dual role of TNF in brain damage and defense.

\section{REFERENCES}

Bachmann R, Eugster HP, Frei K, Fontana A, Lassmann H (1999) Impairment of TNF-receptor-1 signaling but not fas signaling diminishes T-cell apoptosis in myelin oligodendrocyte glycoprotein peptideinduced chronic demyelinating autoimmune encephalomyelitis in mice. Am J Pathol 154:1417-1422.

Bechmann I, Mor G, Nilsen J, Eliza M, Nitsch R, Naftolin F (1999) FasL $(\mathrm{CD} 95 \mathrm{~L}, \mathrm{Apo1L})$ is expressed in the normal rat and human brain: evidence for the existence of an immunological brain barrier. Glia 27:62-74.

Bechmann I, Lossau S, Steiner B, Mor G, Gimsa U, Nitsch R (2000) Reactive astrocytes upregulate fas (CD95) and fas ligand (CD95L) expression but do not undergo programmed cell death during the course of anterograde degeneration. Glia 32:25-41.

Bellgrau D, Duke RC (1999) Apoptosis and CD95 ligand in immune privileged sites. Int Rev Immunol 18:547-562.

Degli-Esposti MA, Dougall WC, Smolak PJ, Waugh JY, Smith CA, Goodwin RG (1997a) The novel receptor TRAIL-R4 induces NFkappaB and protects against TRAIL-mediated apoptosis, yet retains an incomplete death domain. Immunity 7:813-820.

Degli-Esposti MA, Smolak PJ, Walczak H, Waugh J, Huang C-P, DuBose RF, Goodwin RG, Smith CA (1997b) Cloning and characterization of TRAIL-R3, a novel member of the emerging TRAIL receptor family. J Exp Med 186:1165-1170. 
Dörr J, Waiczies S, Wendling U, Seeger B, Zipp F (2001) Induction of TRAIL-mediated glioma cell death by human T cells. J Neuroimmunol, in press.

Flügel A, Schwaiger FW, Neumann H, Medana I, Willem M, Wekerle H, Kreutzberg GW, Graeber MB (2000) Neuronal FasL induces cell death of encephalitogenic T lymphocytes. Brain Pathol 10:353-364.

Frank S, Kohler U, Schackert G, Schackert HK (1999) Expression of TRAIL and its receptors in human brain tumors. Biochem Biophys Res Commun 257:454-459.

Gold R, Hartung HP, Lassmann H (1997) T-cell apoptosis in autoimmune diseases: termination of inflammation in the nervous system and other sites with specialized immune-defense mechanisms. Trends Neurosci 20:399-404.

Griffith TS, Herndon JM, Lima J, Kahn M, Ferguson TA (1995) The immune response and the eye. TCR alpha-chain related molecules regulate the systemic immunity to antigen presented in the eye. Int Immunol 7:1617-1625.

Hilliard B, Wilmen A, Seidel C, Liu TS, Goke R, Chen Y (2001) Roles of TNF-related apoptosis-inducing ligand in experimental autoimmune encephalomyelitis. J Immunol 166:1314-1319.

Huang W-X, Huang MP, Gomes MA, Hillert J (2000) Apoptosis mediators fasL and TRAIL are upregulated in peripheral blood mononuclear cells in MS. Neurology 55:928-934.

Nitsch R, Bechmann I, Deisz RA, Haas DLTN, Wendling U, Zipp F (2000) Massive cell death induced by tumor-necrosis factor-related apoptosis-inducing ligand (TRAIL) in adult human brain tissue. Lancet 356:827-828.

Pan G, O'Rourke K, Chinnaiyan AM, Gentz R, Ebner R, Ni J, Dixit VM (1997a) The receptor for the cytotoxic ligand TRAIL. Science 276:111-113.

Pan G, Ni J, Wei Y, Yu G, Gentz R, Dixit VM (1997b) An antagonist decoy receptor and a death domain-containing receptor for TRAIL. Science 277:815-818.

Pender MP, Nguyen KB, McCombe PA, Kerr JFR (1991) Apoptosis in the nervous system in experimental allergic encephalomyelitis. J Neurol Sci 104:81-87.

Phillips TA, Ni J, Pan G, Ruben SM, Wei YF, Pace JL, Hunt JS (1999) TRAIL (Apo-2L) and TRAIL receptors in human placentas: implications for immune privilege. J Immunol 162:6053-6059.

Pitti RM, Marsters SA, Ruppert S, Donahue CJ, Moore A, Ashkenazi A
(1996) Induction of apoptosis by Apo-2 ligand, a new member of the tumor necrosis factor cytokine family. J Biol Chem 271:12687-12690.

Rieger J, Ohgaki H, Kleihues P, Weller M (1999) Human astrocytic brain tumors express AP02L/TRAIL. Acta Neuropathol (Berl) 97:1-4

Schmied M, Breitschopf H, Gold R, Zischler H, Rothe G, Wekerle H, Lassmann H (1993) Apoptosis of T lymphocytes in experimental autoimmune encephalomyelitis. Evidence for programmed cell death as a mechanism to control inflammation in the brain. Am J Pathol 143:446-452.

Sheridan JP, Marsters S, Pitti RM, Gurney A, Skubatch M, Baldwin D, Ramakrishnan L, Gray CL, Baker K, Wood WI, Goddard AD, Godowski P, Ashkenazi A (1997) Control of TRAIL-induced apoptosis by a family of signaling and decoy receptors. Science 277:818-821.

Song K, Chen Y, Goke R, Wilmen A, Seidel C, Goke A, Hilliard B (2000) Tumor necrosis factor-related apoptosis-inducing ligand (TRAIL) is an inhibitor of autoimmune inflammation and cell cycle progression. J Exp Med 191:1095-1103.

The Lenercept Multiple Sclerosis Study Group and The University of British Columbia MS/MRI Analysis Group (1999) TNF neutralization in MS: results of a randomized, placebo-controlled multicenter study. Neurology 53:457-465.

Tuunanan J, Lukasiuk K, Halonen T, Pitkanen A (1999) Status epilepticus-induced neuronal damage in the rat amygdaloid complex: distribution, time course and mechanisms. J Neurosci 94:473-495.

van Oosten BW, Barkhof F, Truyen L, Boringa JB, Bertelsmann FW, von Blomberg BM, Woody JN, Hartung HP, Polman CH (1996) Increased MRI activity and immune activation in two multiple sclerosis patients treated with the monoclonal anti-tumor necrosis factor antibody cA2. Neurology 47:1531-1534.

Walczak H, Degli-Esposti MA, Johnson RS, Smolak PJ, Waugh JY, Boiani N, Timour MS, Gerhart MJ, Schooley KA, Smith CA, Goodwin R, Rauch CT (1997) TRAIL-R2: a novel apoptosis-mediating receptor for TRAIL. EMBO J 16:5386-5397.

Wendling U, Walczak H, Dörr J, Jaboci C, Weller M, Krammer PH, Zipp F (2000) Expression of TRAIL receptors in human autoreactive and foreign antigen-specific T cells. Cell Death Differ 7:637-644.

Wiley SR, Schooley K, Smolak PJ, Din WS, Huang CP, Nicholl JK, Sutherland GR, Smith TD, Rauch C, Smith CA, Goodwin RG (1995) Identification and characterization of a new member of the TNF family that induces apoptosis. Immunity 3:673-682. 